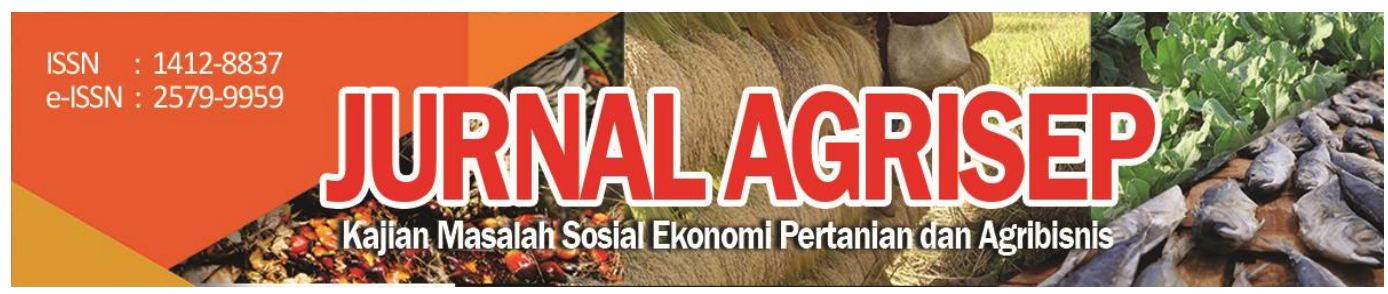

DOI: $10.31186 /$ jagrisep.20.2.355-366

\title{
ANALISIS FINANSIAL DENGAN PENDEKATAN COST VOLUME PROFIT PADA USAHA KOPI BUBUK BUKIT BARISAN DI KABUPATEN BENGKULU TENGAH
}

\section{The Financial Analysis With Cost Volume Profit approach of Bukit Barisan Coffee's In Central Bengkulu Regency}

\author{
Fiqro Ajnus Hervito1) $\square$; Novitri Kurniati2); Elni Mutmainnah ${ }^{3)}$ \\ 1,2,3)Program Studi Agribisnis, Fakultas Pertanian, Universitas \\ Muhammadiyah Bengkulu, Bengkulu, Indonesia \\ Email: fiqro.hervito.10@gmail.com
}

\begin{abstract}
The purpose of this study is to estimate the amount of Bukit Barisan Coffee's operating profit that is reflected in the contribution margin, breakeven point, margin of safety (MOS), degree of operating laverage (DOL) and calculate profit target in next period. The research method used is a case study. The analysis used is cost-volumeprofit analysis (CVP). The data used are primary and secondary data. Based on the results of the analysis, it was found that the profit was IDR 18,323,806 / month with a production of $896 \mathrm{~kg} /$ month, a contribution margin of IDR 21,028,250, a break even point of IDR 6,630,105 and $115 \mathrm{~kg}$ of ground coffee, a MOS value of IDR 44,921,895 and a DOL value of IDR 1.15. The planned profit target of IDR 20,156,186 can be achieved if sell $974 \mathrm{~kg}$ of coffee or get sales of IDR 55,757,635. To achieve the profit target, an alternative scenario is used to increase sales volume by $10 \%$ and a fixed selling price.
\end{abstract}

Keywords: Coffee, Profit, CVP

\section{ABSTRAK}

Tujuan penelitian ini untuk menghitung besar laba usaha Kopi Bukit Barisan yang dicerminkapada margin kontribusi, titik impas, margin of safety (MOS), degree of operating laverage (DOL) dan menghitung target laba yang akan dicapai pada periode selanjutnya.Metode penelitian yang digunakan adalah studi kasus.Analisis yang digunakan adalah cost-volume-profit analisys (CVP). Data yang digunakan adalah data primer dan skunder. Berdasarkan hasil analisis didapat bahwa besar laba yaitu 
Rp18.323.806/bulan dengan produksi $896 \mathrm{~kg} /$ bulan, margin kontribusi sebesar Rp21.028.250, titik impas sebesar Rp 6.630 .105 dan $115 \mathrm{~kg}$ kopi bubuk, nilai MOS sebesar Rp44.921.895 dan nilai DOL sebesar 1,15. Target laba yang direncanakan sebesar Rp20.156.186 dapat dicapai jika menjual sebanyak $974 \mathrm{~kg}$ kopi atau memperoleh penjualan sebesar Rp55.757.635. Untuk mencapai target laba menggunakan alternatif skenario menaikan volume penjualan sebesar 10\% dan harga jual tetap.

Kata Kunci: Kopi, Laba, CVP

\section{PENDAHULUAN}

Provinsi Bengkulu termasuk tiga provinsi yang dikenal sebagai segitiga emas kopi robusta setelah Sumatra Selatan dan Lampung. Pada tahun 2019 Bengkulu berkontribusi pada produksi kopi robusta di Indonesia dengan nilai $12,26 \%$ atau produksi rata-rata 55,37 ribu ton (Ditjenbun, 2019). Dari $36.736 \mathrm{Ha}$ lahan perkebunan kopi Robusta di provinsi Bengkulu, 4.411 Ha berada di kabupaten Bengkulu Tengah (BPS Online Kabupaten Benteng). Sebagian besar merupakan lahan perkebunan rakyat yang kemudian diolah menjadi bubuk kopi dalam bentuk usaha skala rumah tangga. Sehingga hal ini mendorong banyak bermunculan usaha-usaha pengolahan kopi di Bengkulu baik yang berskala kecil maupun sedang yang memiliki tujuan sama yaitu meningkatkan keuntungan.

Kajian finansial perencanaan laba dengan pendekatan CVP (cost-volumeprofit) biasanya dilakukan usaha skala sedang dan besar yang sudah memiliki sistem manajerial yang baik. Analisis CVPdigunakan untuk memperkirakan volume penjualan yang akan mempengaruhi laba perusahaan sehingga dapat dijadikan alat perencanaan bagi manajerial untuk mengevaluasi volume penjualanyang dapat berubah karena perubahan harga,biaya variable dan biaya tetap (Mowen, 2017). Namun untuk usaha kecil jarang dilakukan, padahal suatu usaha dengan perencanaan laba yang tepat akan memberikan motivasi bagi pengusaha kecil dalam rangka peningkatan usahanya. Seperti yang dialami usaha pengolahan biji kopi Kopi Bukit Barisan yang telah memiliki PIRT dan sertifikat halal BPOM. Tujuan dilakukan penelitianuntuk menganalisis finansial dengan pendekatan CVP yang dicerminkan darimargin kontribusi (contribution margin), BEP (break event point), MOS (margin of safety) dan degree of operating laverage (DOL) pada usaha Kopi Bubuk Bukit Barisan di Kabupaten Bengkulu Tengah. Sehingga pemilik usaha bisa menggambil keputusan dalam menaikan laba usaha, perencanaan laba, membuat anggaran perusahaan, target volume penjualan dan target pendapatan untuk bulan selanjutnya menjadi lebih tepat dan akurat.

356 | Fiqro Ajnus Hervito; Novitri Kurniati dan Elni Mutmainnah: Analisis... 


\section{METODE PENELITIAN}

Lokasi penelitian dipilih secara purposivepada usaha pengolahan Kopi Bubuk Bukit Barisan yang berlokasi di Desa Talang Pauh Kecamatan Pondok Kelapa Kabupaten Bengkulu Tengah. Metode penelitian yang digunakan adalah studi kasus dengan teknik pengumpulan data melalui wawancara dan observasi serta studi kepustakaan dan literatur lainnya.

\section{Teknik Analisis Data}

Teknik analisa data yang digunakan dalam penelitian ini adalah analisis deskriftif dan analisis statistik Analisis deskriftif digunakan untuk mendeskripsikan hasil penelitian sedangkan analisa statitik digunakan untuk peramalan biaya dan perencanaan laba. Langkah awal adalah identifikasi biaya, Perhitungan harga pokok produksi dan perhitungan harga pokok penjualan. Kemudian baru dilanjutkan dengan analisis perencanaan laba yang terdiri dari Marjin Kontribusi, BEP, analisis marjin of safety (MOS) dan analisis Degree Operation Leverate (DOL), Garrison (2006) sebagai berikut :

\section{Marjin Kontribusi}

Contribution Margin (Rp) = Penjualan - Biaya Variabel

Contribution Margin Ratio $=\frac{\text { Contribution Margin }}{\text { Penjualan }} \times 100 \%$

Dengan kriteria:

Jika $\mathrm{CM}>\mathrm{FC}=$ Perusahaan akan memperoleh laba

Jika $\mathrm{CM}<\mathrm{FC}=$ Perusahaan akan memperoleh kerugian

Jika $\mathrm{CM}=\mathrm{FC}=$ Perusahaan dalam titik impas

\section{Analisis Titik Impas (BEP)}

Titik Impas $($ Kuantitas $)=\frac{\text { Biaya Tetap }}{\text { Margin Kontribusi }}$

$\operatorname{Titik} \operatorname{Impas}(\mathrm{Rp})=.\frac{\text { BiayaTetap }}{\left(1-\left(\frac{V C}{P}\right)\right)}$

Dengan kriteria:

a. Jika Produksi dan Penjualan $>$ Nilai BEP $=$ untung

b. Jika Produksi dan Penjualan $>$ Nilai BEP = rugi

c. Jika Produksi dan Penjualan $=$ Total Biaya $=$ titik impas

\section{Analisis Margin of Safety}

$$
\text { MOS = Total Penjualan }-\mathrm{BEP}(\mathrm{Rp})
$$


Dengan kriteria:
a. Jika nilai MOS $>0$ maka perusahaan untung
b. Jika nilai $\mathrm{MOS}<0$ maka perusahaan rugi
c. Jika nilai $\mathrm{MOS}=0$ maka perusahaan titik impas.

\section{Analisis Degree Operation Leverate (DOL)}

$$
\mathrm{DOL}=\frac{\text { Marjin Kontribusi }}{\text { Laba Bersih }} \times 100 \%
$$

Dengan kriteria:
a) Jika nilai DOL $>0$ maka kenaikan $1 \%$ penjualan akan meningkatkan laba sebesar nilai DOL.
b) Jika nilai DOL < 0 maka kenaikan 1\% penjualan akan menurunkan laba sebesar nilai DOL.
c) Jika nilai $\mathrm{DOL}=0$ maka kenaikan $1 \%$ penjualan tidak akan mempengaruhi kenaikan atupun penuruanan laba.

\section{Analisis Target Laba}

$$
\begin{aligned}
& \text { Target Volume }(\mathrm{kg})=\frac{\text { Biaya Tetap }+ \text { Target Laba }}{\text { Margin Kontribusi }} \\
& \text { Target Penjualan }(\mathrm{Rp})=\frac{\text { Biaya Tetap }+ \text { Target Laba }}{\text { Rasio Margin Kontribusi }}
\end{aligned}
$$

\section{HASIL DAN PEMBAHASAN}

\section{Identifikasi dan klasifikasi Biaya}

Berdasarkan data yang didapat dari usaha Kopi Bubuk Bukit Barisan, maka diperoleh biaya produksi terdiri dari biaya bahan baku, biaya tenaga kerja, dan biaya overheadpabrik. Biaya tersebut digunakan untuk menunjang proses produksi pada usaha Kopi Bubuk Bukit Barisan.

Jumlah biaya produksi pada usaha Kopi Bubuk Bukit Barisan pada bulan sebelum penelitian adalah Rp30.523.750 lebih rendah dibandingkan dengan bulan sebelum penelitian yaitu Rp32.956.000. Hal ini menunjukan adanya penurunan biaya produksi sebesar Rp2.432.250 dikarenakan adanya pengurangan tenaga kerja berlebih pada sektor penggilingan dan perostingan yang harusnya dua orang menjadi satu orang tenaga kerja pada Usaha Kopi Bubuk Bukit barisan yang menyebabkan menurunya pula biaya produksi.. Penurunan biaya produksi ini berdampak positif bagi perusahaan ini karena dapat menghemat dan memangkas biaya yang harus dikeluarkan oleh perusahaan.

358 | Fiqro Ajnus Hervito; Novitri Kurniati dan Elni Mutmainnah: Analisis... 


\section{Laporan Rugi/Laba Usaha Kopi Bubuk Bukit Barisan}

Laporan rugi laba merupakan ringkasan terdiri dari penjualan, biaya produksi, dan laba bersih.Berdasarkan Laporan Rugi/Laba dari Usaha Kopi Bubuk Bukit Barisan pada bulan penelitian diperoleh laba bersih sebesar Rp18.323.806 lebih besar di bandingkan dengan pada bulan sebelum penelitian yakni sebesar Rp16.800.000. Sedangkan data penjualan pada bulan penelitian sebesar Rp51.552.000 lebih besar dibandingkan dengan data penjualan sebelum bulan penelitian yakni sebesar Rp49.756.000. Hal ini disebabkan meningkatnya permintaan pasar terhadap kopi Bubuk Bukit Barisan dan meluasnya ekpansi pasar yang telah merambat dari sebelumnya hanya memasarkan produknya pada ruko-ruko kecil dan pasar tradisional kini bertambah menjadi penjulan pada gerai-gerai mini market berbasis modern seperti mini market Indomaret sehingga sangat mempengaruhi dari kenaikan volume penjualan. Biaya produksi pada bulan penelitian sebesar Rp30.523.750 lebih rendah dibandingkan dengan bulan sebelum penelitian yaitu Rp32.956.000. Hal ini menunjukan adanya penurunan biaya produksi dikarenakan adanya pengurangan tenaga kerja pada Usaha Kopi Bubuk Bukit barisan yang menyebabkan menurunya pula biaya produksi.

\section{Analisis Perencanaan Laba}

Perencanaan laba adalah jumlah laba yang ingin diperoleh perusahaan melalui aktivitas operasi yang mencakup kegiatan produksi dan penjualan selama periode tertentu. Ada dua cara untuk menganalisis perencanaan laba yaitu marjin kontribusi dan persamaan CVP.

Tabel 1. Analisis Perencanaan Laba Usaha Kopi Bubuk Bukit Barisan

\begin{tabular}{lr}
\hline \multicolumn{1}{c}{ Uraian } & Nilai (Rp) \\
\hline Penjualan (Rp) & 51.552 .000 \\
Biaya Variabel (Rp) & 30.523 .750 \\
Biaya Tetap (Rp) & 2.704 .444 \\
Produksi (kg) & 896 \\
Marjin Kontribusi (Rp) & 21.028 .250 \\
Marjin Kontribusi Per Unit (Rp/kg) & 23.469 \\
Rasio Marjin Kotribusi (\%) & $41 \%$ \\
BEP Unit (kg) & 115 \\
BEP (Rp) & 6.630 .105 \\
MOS & 44.921 .895 \\
Laba Bersih & 18.323 .806 \\
DOL & 1,15 \\
\hline
\end{tabular}

Sumber: Data primer diolah, 2021 


\section{Marjin Kontribusi}

Hasil analisis pada tabel 1 diketahui nilai margin kontribusi usaha Kopi Bubuk Bukit Barisan sebesar Rp21.028.250/bulan. Nilai ini diperoleh dari hasil penjualan dikurangi dengan biaya variabel(Winarko\&Astuti,2018). Nilai margin kontribusi tersebut dapat digunakan oleh pemilik usaha untuk mengetahui sejauh mana pendapatan dari suatu usaha bisa menutupi biaya tetap setelah pemilik usaha mengeluarkan biaya variabel. Pada usaha ini nilai margin kontribusi lebih besar dari pada total biaya tetap yang harus dikeluarkan yaitu sebesar Rp2.704.000.Hal ini menunjukan usaha Kopi Bubuk Bukit Barisan memperoleh keuntungan.

\section{Rasio Marjin Kontribusi}

Nilai rasio margin kontribusi pada usaha Kopi Bubuk Bukit Barisan lebih besar dari $0 \%$ yaitu sebesar $41 \%$. Nilai menunjukan bahwa setiap perubahan penjualan sebesar $1 \%$ akan menyebabkan perubahan total kontribusi margin sebesar $41 \%$ artinya bahwa untuk setiap peningkatan 1 rupiah kenaikan penjualan total margin kontribusi akan meningkat sebesar Rp0,41,-. Total margin kontibusi akan meningkat pula dengan asumsi tidak ada perubahan biaya tetap.

\section{Titik Impas (BEP)}

Menurut Bustami (2010), analisis Break Event Point atau titik impas adalah suatu keadaan dimana perusahaan dalam operasinya tidak memperoleh laba ataupun menderita kerugian atau dengan kata lain total biaya sama dengan total penjualan, sehingga tidak ada laba dan tidak ada rugi. Analisis ini juga bisa digunakan oleh pemilik usaha untuk melihat berapa unit yang harus dijual agar pemilik usaha dapat memperoleh keuntungan baik segi volume penjualan ataupun dalam rupiah

Berdasarkan tabel 1. Nilai titik impas per kilogramnya sebesar $115 \mathrm{~kg}$, sedangkan BEP penjualan (Rp) didapat sebesar Rp6.630.105. Dalam hal ini jika usaha Kopi Bubuk Bukit Barisan menjual minimum sebanyak $115 \mathrm{~kg}$ kopi bubuk/bulan dan penjualan minimal sebesar Rp6.630.105/bulan maka usaha ini dapat menutupi semua biaya pada perusahaan agar tidak menderita kerugian dan tidak pula mendapat keuntungan sama sekali atau perusahaan dalam titik impas.Tapi pada penelitian lapangan usaha ini dapat menjual diatas nilai titik impas yakni 896 kilogram bubuk kopi atau penjualan sebesar Rp51.552.000. Hal ini menunjukan usaha ini memperoleh profit.

\section{Analisis Marjin of Safety (MOS)}

Nilai MOS untuk usaha Kopi Bubuk Bukit Barisan pada bulan penelitian adalah Rp44.921.895/bulan.Dengan menegetahui nilai MOS ini, berguna untuk 
pemilik usaha Kopi Bubuk Bukit Barisan mengetahui seberapa besar penjualan yang boleh turun sebelum perusahaan mengalami kerugian dan pemilik usaha juga dapat menjaga perusahaan dari kemungkinan kerugian. Pada penelitian ini, usaha Kopi Bubuk Bukit Barisan boleh turun hingga Rp44.921.895. Hal ini menunjukan bahwa usaha Kopi Bubuk Bukit Barisan mempunyai resiko yang sangat rendah untuk mengalami kerugian yang disebabkan penurunan penjualan baik karena persaingan bisnis, kemerosotan ekonomi maupun perubahan perilaku konsumen, karena nilai MOS pada usaha ini yang tinggi.

\section{Analisis Degree of Operating Leverage (DOL)}

Nilai DOL untuk usaha Kopi Bubuk Bukit Barisan pada bulan penelitian adalah 1,15. Implementasi dari nilai DOL sendiri untuk pemilik usaha sendiri adalah dapat mengetahui seberapa besar pengaruh kenaikan atau penurunan laba bersih terhadap perubahan volume penjualan (Garisson, 2006). Nilai inimenunjukan setiap kenaikan 1 persen penjualan akan meningkatkan laba bersih sebesar 1,15 persen dan sebaliknya. Semakin tinggi nilai DOL, maka semakin tinggi pula laba bersih yang akan diterima.

\section{Target Laba}

Menurut Garrison, et al(2008) analisis target laba dapat digunakan untuk menentukan volume penjualan yang dibutuhkan untuk mencapai target laba. Analisis biaya volume dan laba dapat digunakan untuk menentukan banyaknya unit yang harus di produksi atau rupiah penjualan yang harus dilaksanakan oleh pemilik usaha guna mencapai target laba yang diinginkan.

Kenaikan laba yang diinginkan pada bulan Februari sebesar 10\%. Berikut merupakan perhitungan target laba pada bulan Februari dengan melihat laba dari bulan Januari.

$$
\begin{array}{ll}
\text { Laba bulan Januari } & =\text { Rp18.323.806 } \\
\text { Laba yang diinginkan } & =10 \% \\
\begin{aligned}
\text { Laba yang diharapkan } & =\text { laba bulan Januari }+(10 \% \times \text { laba bulan Januari }) \\
& =18.323 .806+(10 \% \times 18.323 .806) \\
& =\text { Rp20.156.186 }
\end{aligned}
\end{array}
$$

Setelah melakukan perhitungan untuk menentukan target laba yang ingin dicapai pada bulan Februari dengan kenaikan yang diharapkan sebesar 10\% dari bulan Januari sebesar Rp18.323.806 menajadi Rp20.156.186 pada bulan Februari.

Perhitungan analisis target laba dengan mengunakan metode kontribusi margin untuk mengetahui besarnya volume penjualan yang harus dilakukan Usaha Kopi Bubuk Bukit Barisan agar mencapai target laba yang diinginkan (Samryn 2012): Berdasarkan hasil perhitungan usaha Kopi Bubuk Bukit Barisan telah merencanakan target laba sebesar Rp20.156.186. Target laba tersebut akan dapat tercapai jika Usaha Kopi Bubuk Bukit Barisan dapat menjual sebanyak 
974 kg kopi bubuk atau memperoleh penjulan sebesar Rp55.757.635 pada bulan selanjutnya.

Menurut Iswara dan Susanti (2017), manajer juga harus bisa mengambil keputusan bisnis yang tepat agar dapat bertahan dalam persaingan pasar yang ada dan untuk memperkecil kegagalan, manajer dapat melakukan beberapa langkah untuk laba yang optimal yaitu: 1) menekan biaya operasional serendah mungkin dengan mempertahankan tingkat harga dan volume penjualan, 2) menentukan tingkat harga sedemikian rupa sesuai dengan laba yang dikehendaki, dan 3) meningkatkan volume penjualan sebesar mungkin

Dari beberapa hasil analisis CVP yang sudah dilakukan, maka akan dipilih cara mana yang dianggap paling rasional dan sesuai yang dapat dilakukan oleh Usaha Kopi Bubuk Bukit Barisan sesuai dengan kondisi usaha dan kondisi pasar yang ada.

Tabel 2. Alternatif Skenario Untuk Mencapai Target Laba

\begin{tabular}{lccc}
\hline \multirow{2}{*}{ Parameter } & \multicolumn{3}{c}{ Skenario } \\
\cline { 2 - 4 } & A & B & C \\
\hline Harga Jual & Naik $5 \%$ & Tetap & Naik 2,5\% \\
Volume Penjualan & Tetap & Naik $10 \%$ & Tetap \\
Biaya Tetap & Tetap & Tetap & Turun 25\% \\
\hline
\end{tabular}

Dengan asumsi biaya dan penjualan sama dengan bulan Januari 2021, maka analisis CVP dari alternatif skenario yang mungkin digunakan untuk bulan Februari 2021 agar mencapai target laba yang diinginkan dapat diliat pada tabel 2.

Tabel 3. Skenario Untuk Mencapai Target Laba

\begin{tabular}{lrrrr}
\hline \multirow{2}{*}{ Uraian } & Penjualan & \multicolumn{3}{c}{ Skenario } \\
\cline { 3 - 5 } & Bulan Januari & \multicolumn{1}{c}{$\mathrm{A}$} & \multicolumn{1}{c}{$\mathrm{B}$} & \multicolumn{1}{c}{$\mathrm{c}$} \\
\hline Produksi (Kg) & 896 & 896 & 985,6 & 896 \\
Penjualan & 51.552 .000 & 54.129 .600 & 56.707 .200 & 52.840 .800 \\
Biaya Variabel & 30.523 .750 & 30.523 .750 & 33.576 .125 & 30.523 .750 \\
CM & 21.028 .250 & 23.605 .850 & 23.131 .075 & 22.317 .050 \\
Biaya Tetap & 2.704 .444 & 2.704 .444 & 2.704 .444 & 2.028 .333 \\
Laba & 18.323 .806 & 20.901 .406 & 20.426 .631 & 20.288 .717 \\
BEP Penjualan & 6.630 .105 & 6.201 .449 & 6.630 .105 & 4.802 .550 \\
Taget Laba & 20.156 .186 & 20.156 .186 & 20.156 .186 & 20.156 .186 \\
10\% & & & & \\
\hline
\end{tabular}

Sumber: Data primer diolah, 2021

362 | Fiqro Ajnus Hervito; Novitri Kurniati dan Elni Mutmainnah: Analisis... 
Ketiga hasil perhitungan menurut skenario alternatif untuk mencapai target laba tersebut dapat dijelaskan sebagai berikut:

\section{Menaikan harga jual $5 \%$ dan volume penjualan tetap}

Harga jual yang dinaikan sebesar 5\% diharapkan mampu menaikan penjualan dan laba yang diterima oleh usaha Kopi Bubuk Bukit Barisan. Menaikan harga sebesar 5\% masih dalam tahap wajar dan masih dapat diterima oleh konsumen karena harga yang ditetapkan oleh pemilik usaha masih berada dibawah harga pesaingnya, selain itu produk usaha Kopi Bubuk Bukit Barisan ini juga telah terdaftar pada izin P-IRT dengan adanya izin ini tanda bahwa produksi kopi tersebut layak untuk dijual. Menaikan harga jual masih memungkinkan dikarenakan produk yang dijual sudah terjamin kualitas dan rasanya.

\section{Menaikan volume penjualan 10\% dan harga jual tetap}

Alternatif skenario kedua adalah untuk mencapai target laba yang telah direncanakan dari penjualan bulan sebelumnya yaitu menaikan volume penjualan sebesar $10 \%$ dengan harga jual tetap. Hal ini masih memungkinkan dilakukan karena pemilik usaha telah memperluas jangkauan penjualannya seperti penjualan diplatform online shop dan menaruh ke pasar baru yang belum terjangkau.Hal ini juga yang menjadi alasan mengapa menaikan volume penjualan sebesar $10 \%$ dapat dicapai untuk bulan selanjutnya.

\section{Menurunkan biaya tetap 25\% dan menaikan harga jual 2,5\%}

Alternatif skenario terakhir adalah dengan menurunkan biaya tetap sebesar 25\% dan menaikan harga jual perusahaan sebesar 2,5\% Hal ini masih memungkinkan dilakukan oleh pemilik usaha Kopi Bubuk Bukit Barisan untuk menurunkan biaya tetap sebesar $25 \%$ tersebut karena ada beberapa komponen dari biaya tetap yang masih bisa dikurangi seperti biaya sewa tempat karena tempat usaha milik pribadi. Komponen biaya tersebut merupakan biaya yang masih dapat diminimalisir pengeluarannya oleh pemilik usaha.

Dari semua alternatif yang telah dibuat sebenarnya dapat dijadikan pilihan oleh pemilik usaha Kopi Bubuk Bukit Barisan, tetapi alternatif yang memungkinkan dipilih dan dijadikan alternatif terbaik untuk diterapkan pada usaha Kopi Bubuk Bukit Barisan adalah alternatif kedua yaitu menaikan volume penjualan sebesar $10 \%$ dan harga jual tetap. Hal ini dikarenakan pemilik usaha setiap harinya memperluas jangkauan pendistribusian produknya ke pasar-pasar baru yang belum dijangkau sebelumnya mulai dari toko-toko klontong di Kabupaten Bengkulu Tengah dan beberapa minimarket di Kecamatan Kota Bengkulu. 


\section{SIMPULAN DAN SARAN}

\section{Simpulan}

Besarnya laba yang diperoleh Usaha Kopi Bubuk Bukit Barisan yaitu sebesar Rp18.323.806/bulan dengan jumlah produksi kopi bubuk sebanyak 896 $\mathrm{kg} /$ bulan.

Analisis CVP Usaha Kopi Bubuk Bukit Barisanmenunjukkan nilai Margin kontribusi sebesar Rp21.028.250. Titik impas sebesar Rp6.630.105 atau sebesar $115 \mathrm{~kg}$ kopi bubuk.Batas keamanan atau Margin of Safety (MOS) yakni sebesar Rp44.921.895 sehingga untuk menderita kerugian sangat rendah. Nilai DOL yang dimiliki sebesar 1,15 yang berarti apabila penjualan naik $1 \%$ maka laba akan naik sebesar $1,15 \%$.

Target laba yang direncanakan oleh usah Kopi Bubuk Bukit Barisan sebesar Rp20.156.186 akan dapat dicapai jika menjual sebanyak 974 kg kopi bubuk atau memperoleh penjulan sebesar Rp55.757.635. Alternatif skenario untuk mencapai target laba yaitu: 1) menaikan harga jual sebesar 5\% dan volume penjualan tetap, 2) menaikan volume penjulan sebesar $10 \%$ dan harga jual tetap dan 3) menurunkan biaya tetap sebesar $25 \%$ dan menaikan harga jual sebesar $2,5 \%$.

\section{Saran}

Agar laba terus meningkat maka usaha Kopi Bubuk Bukit Barisan sebaiknya memperluar pasar seperti penjualan produk melalui aplikasi belanja online maupun menjangkau pasar pasar modern lainya. Alternatif kedua dapat dipilih jika ingin menaikan target laba yaitu menaikan volume penjualan sebesar $10 \%$ dan harga jual tetap.

\section{DAFTAR PUSTAKA}

Arizal, M. F., Dzulkirom, M., dan Rahayu, S, M. 2016. Analisis Cost Volem Profit Sebagai Dasar Perencanaan Harga Jual Dan Laba Yang Diharapkan. Jurnal Adminisitrasi. 13(2): 1-8

Assa, R. 2013. Analisis Cost-Volume-Profit (CVP) Dalam Pengambilan Keputusan Perencanaan Laba Pada PT.Tropica Cocoprima. Jurnal Riset Ekonomi, Manajemen, Bisnis Dan Akuntansi. 1(3): 591-601

Buata, N., Ilat, V., dan Pangemanan, S, S. 2015. Analisis Perencanaan Laba Perusahaan Melalui Penerapan Break Even Point Pada PT. Tira Austenite Tbk Bitung. Manado. Jurnal Riset Ekonomi, Manajemen, Bisnis Dan Akuntansi. 3(1): 612-620

364 | Fiqro Ajnus Hervito; Novitri Kurniati dan Elni Mutmainnah: Analisis... 
Budiwibowo, S. 2012. Analisis Estimasi Cost Volume Profit (CVP) Dalam Hubungannya Dengan Perencanaan Laba Pada Hotel Tlogo Mas Sarangan. Assets. Jurnal Akuntansi dan Pendidikan. 1(1): 13-23

Direktorat Jenderal Perkebunan. 2019. Buku Outlook Komoditas Perkebunan Kopi. Jakarta: Direktorat Jenderal Perkebunan, Kementerian Pertanian

Dua, M, D., Rahayu, S, M., dan Zahro. 2015. Penerapan Cost Volume Profit Analysis Sebagai Dasar Perencanaan Penjualan Pada Tingkat Laba Yang Diharapkan Studi Pada Perusahaan Paving Block CV ETERNA Mergosono Malang. Jurnal Administrasi Bisnis. 27(1): 1-9

Duyo, S, F. 2013. Analisis Cost Volume Profit Untuk Perencanaan Laba Pada Hotel Sintesa Peninsula Manado. Jurnal Riset Ekonomi, Manajemen, Bisnis Dan Akuntansi. 1(3): 603-610

Garrison, N dan Brewer. 2008. Akuntansi Manajerial. Jakarta: Salemba Empat

Iswara, U, S., dan Susanti. 2017. Analisis Cost Volume Profit Sebagai Dasar Perencanaan Laba Yang Diharapkan (Study Pada Perusahaan Kopi di Kabupaten Jember). Jurnal Riset Akuntansi Keuangan. 2(2): 67-76

Lasena, S, R. 2016. Analisis Penentuan Harga Pokok Produksi Pada PT. Dimembe Nyiur Agripo. Jurnal Riset Ekonomi, Manajemen, Bisnis Dan Akuntansi. 1(3): 585-592

Malombeke, M, B. 2017. Analisa Break Even Point Sebagai Dasar Perencanaan Laba Holland Bakery Manado. Jurnal Riset Ekonomi, Manajemen, Bisnis Dan Akuntansi. 1(3): 775-881

Mangundap dan Reisty. 2016. Break Even Point Sebagai Alat Perencanaan Laba Jangka Pendek Pada Shmily Cupcakes. Jurnal Riset Ekonomi, Manajemen, Bisnis Dan Akuntansi. 2(4): 117-232

Marvita, R. 2017. Cost Volume Profit (CVP) Sebagai Alat Perencanaan Laba Pad Apt Indo Tambangraya Megah, Tbk Dan Entitas Anak. Jurnal FinAcc. 1(10): 1756-1770

Retno, A., Rahayu, S, M., dan Husaini, A. 2014. Analisis Break Even Point Sebagai Dasar Pengambilan Keputusan Manajemen Terhadap Perencanaan Volume Penjualan Dan Laba. Jurnal Adminitrasi Bisnis. 11(1): $1-10$

Martusa, R dan Putri, R, D, A. 2018. Penerapan Cost Volume Profit Analysis Sebagai Alat Bantu Dalam Perencanaan Penjualan Atas Target Laba Yang Ditetapkan Studi Kasus Pada Tokoh Mei Pastry.Akurat Jurnal Ilmiah Akuntasnsi. (3): 1-19

Sihombing, S, B. 2019. Analisis Biaya VolumeLaba Sebagai Alat Bantu Perencanaan Laba PT. Bangun Wenang Beverages Company. Jurnal Riset Ekonomi, Manajemen, Bisnis Dan Akuntansi. 1(3): 181-188 
Pangemanan, J, T. 2016. Analisis Perencanaan Laba Perusahaan Dengan Penerapan Break Even Point Pada PT Kharisma Sentosa Manado. Jurnal Riset Ekonomi, Manajemen, Bisnis Dan Akuntansi. 4(1): 376-385

Wahyuni, S. 2017. Analisis Biaya Volume Laba Melalui Alokasi Biaya Bersama Sebagai Perencanaan Laba. Jurnal Akuntansi. 3(2):15 - 26

Winarko, S, P. dan Astuti, P. 2018. Analisis Cost Volume Profit Sebagai Alat Bantu Perencanaan Laba (Multi Produk) Pada Perusaaan Pia Latief Kediri. Jurnal Nusantara Aplikasi Manajemen Bisnis. 3(2): 9-21

Worotitjan, E, E dan Manossoh, H. 2016. Analisis Cost Volume Profit untuk Perencanaan Laba pada UD. Gunung Emas Manado. Jurnal Riset Ekonomi, Manajemen, Bisnis Dan Akuntansi. 4(1): 585-592

Zaini, M. 2017. Analisi Keuntungan dan Titik Impas Rumah Tangga Tahu di Kecamatan Punggur, Lampung. Jurnal Ilmiah ESAI. 1(1): 1-5 